\title{
AVALIAÇÃO PÓS-OCUPAÇÃO DE PROJETO PADRÃO DO PROINFÂNCIA EM RECIFE-PE
}

\author{
NASCIMENTO, Karoline Lima \\ Universidade Federal de Pernambuco, e-mail: karoline.tg.ufpe@gmail.com \\ LIMA, Ana Clara Cavalcanti de \\ Centro Universitário UniFBV, e-mail: limaanaclara@hotmail.com
}

\begin{abstract}
RESUMO
Entendendo a importância da eficiência dos projetos padronizados, principalmente os destinados a públicos com características programáticas bastante específicas como crianças, delimitou-se como objeto de pesquisa a creche-escola Presidente Tancredo Neves, localizada no bairro do Barro, na cidade do Recife-PE. O objetivo principal foi utilizar os instrumentos da Avaliação Pós Ocupação (APO) aplicados a um tipo de projeto padrão, disponibilizado pelo sistema Proinfância, um programa público de escala nacional que visa a construção de equipamentos educacionais a fim de melhorar a qualidade da educação pública oferecida a infância. Foram utilizados como métodos de investigação a Observação assistemática, Walkthrough, Questionários, Entrevistas e Mapas mentais. O trabalho buscou explicitar a importância do projeto para infância, pois ele pode comprometer atividades pedagógicas e o desenvolvimento infantil. A análise dos resultados apontou que o projeto padrão da creche necessita de alterações para melhorias do seu desempenho térmico e mudanças formais, como alteração na implantação dos blocos. Entende-se também que a difusão de pesquisas e experiências em APO contribui para um melhor entendimento da vivência e interação do homem com o espaço construído, para a atuação dos profissionais e estudantes de arquitetura e urbanismo e áreas afins, além do estímulo a novas investigações na área.
\end{abstract}

Palavras-chave: Avaliação Pós-Ocupação, Creche, Padronização, Proinfância.

\begin{abstract}
Understanding the importance of the efficiency of standardized projects, mainly the ones intended to the public with programmatic characteristics, such as children. The research object has been narrowed down to the School Daycare President Tancredo Neves, located in the neighborhood Barro, Recife-PE. The main objective was to use the instruments of Post-occupancy evaluation applied to a type of standard project that has been made available by the Proinfância system, a public program of national scale which aims at the construction of educational equipments, in order to improve the quality of public education offered to the youth. Many research methods were used, such as unsystematic observation, Walkthrough, Quizes, Interviews and Mental Maps. The work sought to make explicit the importance of the project to the youth, because it could compromise pedagogical activities and the children development. After analyzing the results, we found that the standardized project for the Daycare needs some change in order to improve thermal performance and some formal alterations in the implementation of the blocks. It is also understood that the dissemination of research and experiences in POE contributes to a better understanding of the experience and interaction of man with the built space, for the performance of professionals and students of architecture and urbanism and related areas, as well as stimulating new investigations in the area.
\end{abstract}

Keywords: Post-occupancy evaluation, Day care, Standardization, Proinfância.

NASCIMENTO, K. L.; LIMA, A. C. C. Avaliação Pós-Ocupação de projeto padrão do Proinfância em Recife-PE. In: SIMPÓSIO BRASILEIRO DE QUALIDADE DO PROJETO NO AMBIENTE CONSTRUÍDO, 6., 2019, Uberlândia. Anais... Uberlândia: PPGAU/FAUeD/UFU, 2019. p. 1142-1152. DOI https://doi.org/10.14393/sbqp19104. 


\title{
1 INTRODUÇÃO
}

Por definição do Dicionário Michaelis, a palavra 'infância' significa "período da vida, no ser humano, que vai desde o nascimento até o início da adolescência". Apresenta ainda as definições das fases da infância, que são a primeira infância, que vai do nascimento até os primeiros três anos de idade; a segunda infância, que vai dos três aos seis anos de vida e a terceira infância, que vai dos seis aos doze anos de idade, uma vez que o Estatuto da Criança e do Adolescente (ECA), Lei nº 8.069 de 13 de julho de 1990, considera a infância até os doze anos de vida.

De acordo com a Fundação Marilia Cecilia Souto Vidigal, que busca promover o desenvolvimento integral da criança e desenvolvem projetos de impacto na infância, a primeira infância é uma época de muita importância pois as experiências e o desenvolvimento dessa fase são levados para o resto da vida, e são muito influenciados pela realidade em que a criança está inserida. Estudos também apontam que a possibilidade desta se tornar um adulto mais equilibrado e positivo são maiores quando as condições para o desenvolvimento da primeira infância são boas e estimulam que ela alcance o melhor do seu potencial'.

Dentro dessa perspectiva, Rousseau afirma que cada fase da vida possui características próprias e tanto o homem quanto a sociedade modificam-se, sendo a educação o elemento fundamental para a necessária adaptação a essas modificações. Assim, a educação não vem de fora, mas é a expressão livre da criança no seu contato com a natureza, elevando ainda mais a importância do ambiente escolar, que deve ser uma resposta à proposta pedagógica que a escola pretende adotar (KOWALTOWSKI, 2011, p. 17).

\begin{abstract}
A evolução intelectual da criança é acompanhada por alterações dimensionais tão rápidas e distintas quanto a diversidade humana. Com o desenvolvimento, aumentam a qualidade e a quantidade de informações sensoriais que serão processadas pela criança. Cabe observar que nessa evolução, e consequente aumento da carga perceptiva, o ambiente a ser vivenciado pela criança pequena deve estar voltado para um fator importante: a segurança. A segurança, por sua vez, está diretamente ligada à capacidade individual de ação por parte dessas crianças; pode-se dizer que a segurança das crianças pequenas em relação a um determinado ambiente depende da capacidade de perceber 0 ambiente adequadamente, diminuindo assim os riscos envolvidos na ação. É necessário, então, que os ambientes sejam facilitadores da percepção direta, dos limites possíveis de ação, e da construção de imagens realistas e amplas sobre as possibilidades de ação individual (BLOWER, 2008, p. 27).
\end{abstract}

Por isso, não apenas as características do espaço são importantes, mas, a forma como esse espaço será aproveitado dentro do projeto pedagógico da instituição, a qualidade dos profissionais que lá trabalham e "principalmente, se $\mathrm{o}$ ambiente proporciona segurança e acolhimento para que a criança

1 FUNDAÇÃO MARILIA CECILIA SOUTO VIDIGAL. Disponível: <http://www.fmcsv.org.br>. Acesso em: 20 mar. 2018. A fundação é uma instituição sem fins lucrativos, fundada em 2007, com a finalidade de desenvolver projetos focados na primeira infância, através de iniciativas voltadas à promoção do desenvolvimento integral das crianças. Fonte: <http://www.fmcsv.org.br>. Acesso em 20 abr. 2018. 
possa experimentar novas sensações"2. Dessa forma, a preocupação com a qualidade dos ambientes educacionais deve estar entre as preocupações dos arquitetos, projetistas, construtores e profissionais afins.

Uma excelente ferramenta para avaliar a qualidade desses ambientes é a Avaliação Pós-Ocupação (APO). De acordo com Ornstein (1992), é uma ferramenta utilizada para mensuração do desempenho dos edifícios durante o seu uso a partir do entendimento das técnicas aplicadas a uma construção e os impactos negativos e positivos que se obteve após sua ocupação e consequente utilização.

Ornstein (1992) defende também que esse instrumento ganha relevância por considerar não apenas a visão do pesquisador, mas também a satisfação dos usuários a partir de métodos e técnicas que geram diagnósticos completos e consistentes sobre os aspectos negativos e positivos do ambiente construído, servindo dessa forma para fundamentar e embasar as recomendações e intervenções. Além disso, ela é importante, pois se incorpora como mais uma fase do ciclo programa/projeto/execução, ou seja, quando a edificação passa a desempenhar as funções de abrigar as atividades humanas, de forma a garantir a sua manutenção da sua qualidade (ELALI, 2002). Esse ciclo realimentador do projeto pode ser usado na avaliação de políticas públicas como a do programa Proinfância - a fim de aperfeiçoa-las a partir da satisfação ou insatisfação dos usuários/moradores e da qualidade construtiva final (ORNSTEIN, 1992).

A creche escolhida como objeto de estudo empírico foi a Creche-Escola Presidente Tancredo Neves, localizada no bairro do Barro, na cidade do Recife -PE. A escolha se deu por ser o único equipamento construído nos moldes da cartilha do Proinfância na cidade, até a data da realização da pesquisa. A creche-escola utilizou o projeto padrão tipo "B" do Proinfância, desenvolvido para atender até 224 crianças, em dois turnos (matutino e vespertino) ou 112 crianças, em turno integral e considera como tipo de terreno ideal, para esse empreendimento, um terreno retangular com medidas de $40 \mathrm{~m}$ de largura por $70 \mathrm{~m}$ de profundidade e declividade máxima de $3 \%$.

\section{OBJETIVO}

Esta pesquisa tem como alvo a eficiência de um projeto que é padrão do Programa Proinfância - a Creche - Escola Presidente Tancredo Neves, com relação a sua organização espacial e física, e dos materiais utilizados na construção e os seus impactos gerados no desempenho climático, e no bemestar dos usuários, por meio de uma Avaliação Pós-Ocupação.

\section{METODOLOGIA}

Neste ponto, foram expostos os instrumentos metodológicos utilizados durante a pesquisa e a justificativa da escolha de cada um. Ressalta-se que, segundo Rheingantz et al. (2009, p.14), tais métodos não buscam trazer verdades absolutas, pois não conseguem por si só apreender todas as experiências vivenciadas por diferentes sujeitos em um mundo não pré-definido. Dessa forma, "os resultados da aplicação de um conjunto de instrumentos devem ser

2 HUNGRIA (08/05/2018). 
complementos capazes de corroborar a experiência reflexiva e intuitiva vivenciada durante a observação".

\title{
3.1 Observação assistemática
}

Consiste na observação não estruturada, de forma simples. É definida como uma observação feita "de forma livre e sem qualquer planejamento prévio. Muito útil para as etapas inicias da pesquisa no sentido de conhecer melhor 0 problema" (OLIVEIRA, 2009, p. 106).

Foi utilizada para uma avaliação inicial da configuração espacial da creche, visando coletar informações relativas à edificação, além disso, acerca do comportamento dos usuários - alunos, funcionários (gestores, professores, serviços gerais) e pais. É uma observação sem um caminho pré-definido, mas que permite o reconhecimento do objeto de estudo e ajuda na determinação das técnicas seguintes a serem aplicadas. Nessa etapa inicial, foram feitas anotações e os primeiros registros fotográficos.

\subsection{Walkthrough}

O Passeio Acompanhado - Walkthrough é uma técnica criada por Kevin Linch e que combina a observação com a entrevista de forma simultânea. É descrito por Rheingantz et al. (2009, p.23) como a ferramenta que

\begin{abstract}
em geral precede a todos os estudos e levantamentos, sendo bastante útil para identificar as principais qualidades e defeitos de um determinado ambiente construído e de seu uso. Sua realização permite identificar, descrever, hierarquizar, quais aspectos desse ambiente ou de seu uso merecem estudos mais aprofundados e quais técnicas e instrumentos devem ser utilizados. Além disso, ela também permite identificar as falhas, os problemas e os aspectos positivos do ambiente analisado.
\end{abstract}

Com a duração de uma hora e meia, aproximadamente, a visita foi guiada pela gestora da instituição, que apresentou todos os espaços e explicou o funcionamento da creche-escola. Ao decorrer do percurso foram observados aspectos contextuais ambientais, como o acesso, a localização, as vias que circundavam, a topografia, a ventilação, os ruídos, a insolação, entre outros; aspectos programáticos funcionais, como a organização espacial, o conjunto pedagógico, o conjunto de vivência/assistência, o administrativo/apoio técnico, o conjunto de serviços, as circulações, os acessos principais, o mobiliário e layout, a escala do edifício, os percursos, a acessibilidade, a integração interior/exterior, entre outros; aspectos estéticos-compositivos, como as cores, texturas, formas, proporções, superfícies, princípios compositivos, entre outros, e os aspectos técnicos construtivos, como os materiais, manutenção/durabilidade, os revestimentos, entre outros.

\subsection{Questionários}

Os questionários foram fundamentais para a análise do ponto de vista dos usuários, sendo possível também fazer o cruzamento entre as respostas. No caso de uma APO "a análise dos resultados obtidos com a aplicação do questionário possibilita identificar o perfil dos respondentes e verificar sua opinião acerca dos tributos ambientais analisados" (RHEINGANTZ et al, 2009, p.79). 
Foram aplicados 47 questionários, sendo $10 \mathrm{com}$ professores, $1 \mathrm{com}$ a coordenadora pedagógica, 1 com o chamado "agente administrativo escolar", que exerce a função de auxiliar administrativo, 15 com os auxiliares de desenvolvimento infantil e 20 com os auxiliares de desenvolvimento infantil estagiário. As perguntas traziam opções de resposta em escala de 1 a 5, sendo 5 o nível mais alto de satisfação e 1 o nível mais baixo de insatisfação, e envolviam questões relacionadas a localização da creche, a manutenção do ambientes, aos materiais de acabamento, aos níveis de conforto térmico, de ruído, a qualidade da ventilação, a quantidade de materiais disponíveis para atividades externas as salas de aula, o dimensionamento das salas, o mobiliário e adequação do mesmo, entre outras.

\subsection{Entrevista}

Ela foi realizada com a gestora da instituição, de forma estruturada, com um roteiro impresso e a pedido da mesma, não foi gravada. Foram realizadas 20 perguntas, entre as quais estavam:

- Qual as atividades educacionais, de lazer, culturais, religiosas e assistência a saúde são prestadas pela instituição?

- Quais as maiores dificuldades/reclamações apresentadas com relação a estrutura física da creche?

- A creche foi construída segundo todos os parâmetros definidos na cartilha do Proinfância para a tipologia implantada? Caso a resposta seja não, o que não seguiu a cartilha e por quê?

- A quantidade de profissionais tem sido suficiente para a demanda de crianças atendidas?

\subsection{Mapas cognitivos}

No lugar de formulários com as crianças, foi utilizado o mapa cognitivo, uma vez que é possível uma melhor expressão das crianças pelo desenho, ainda mais em virtude da idade das crianças, cuja faixa etária variava entre 3 e 5 anos de idade.

Cada criança recebeu folhas de ofício em branco e canetas coloridas e foram orientadas a desenhar, primeiramente, o que a creche-escola representava para elas, quais os locais que mais gostavam, assim como o que mais gostavam na instituição. Em seguida, em outra folha, foram orientadas a desenhar o que gostariam que a creche-escola tivesse. A atividade durou aproximadamente uma hora.

\section{RESULTADOS}

A maioria das crianças que frequenta a creche é proveniente do próprio bairro do Barro, mas ela também atende crianças de bairros próximos, como Areias, Jardim São Paulo e Estância, como visto na Figura 1. A instituição foi uma ação da Prefeitura Municipal da Cidade do Recife, que visou à implementação de um equipamento de educação infantil público para atender aos moradores dos bairros que compõem a Região PolíticoAdministrativa 5 (RPA 5). Por isso, seu quadro funcional é composto, em sua maioria, por funcionários concursados da Prefeitura e alguns também são pais dos alunos. 


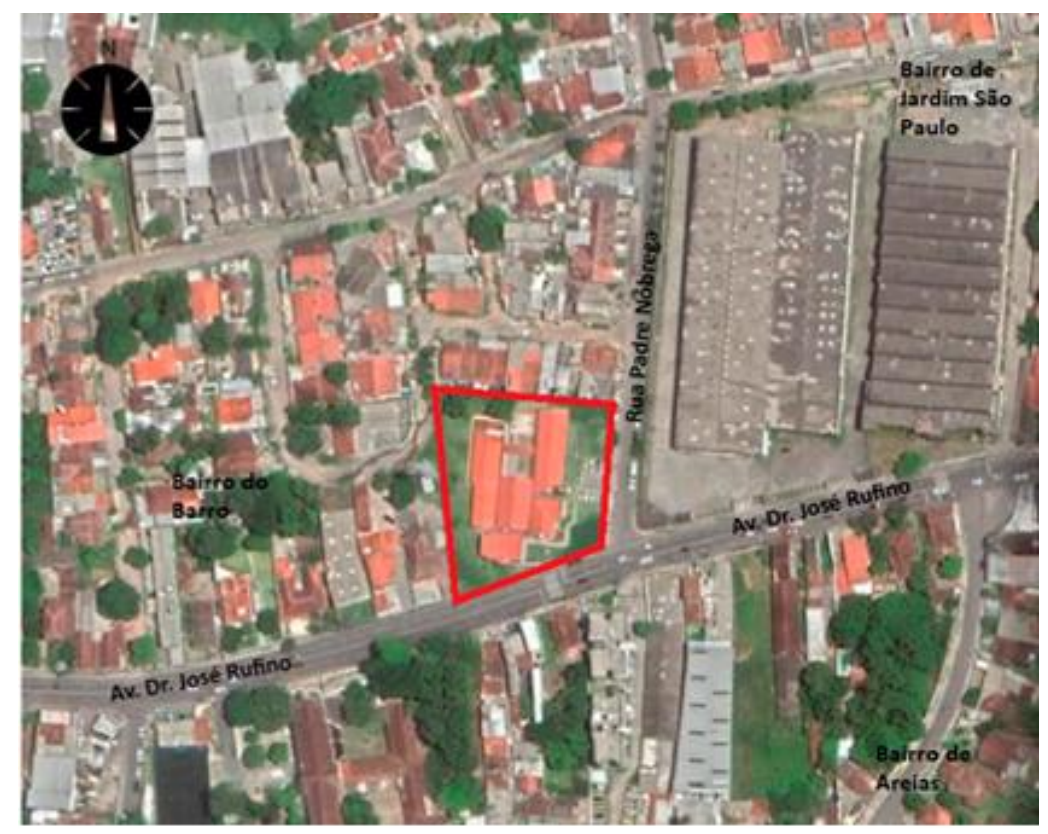

Figura 1 - Localização da creche e proximidades -

Fonte: Adaptada pelas autoras do Google Earth (2018)

A adoção de um projeto padrão dificulta a adaptação climática por não levar em consideração as características climáticas de cada região, e por isso, a primeira observação feita foi referente à implantação do projeto no terreno. Os blocos foram distribuídos nos seguintes setores: (1) administrativo, (2) pedagógico, que abrange dois blocos, e (3) bloco de serviços, todos dispostos ao redor de um pátio central (4), onde também se encontra o refeitório, integrado ao pátio coberto (figura 02). Os blocos são todos voltados para o pátio central e para a área do parque infantil, ao fundo (5).

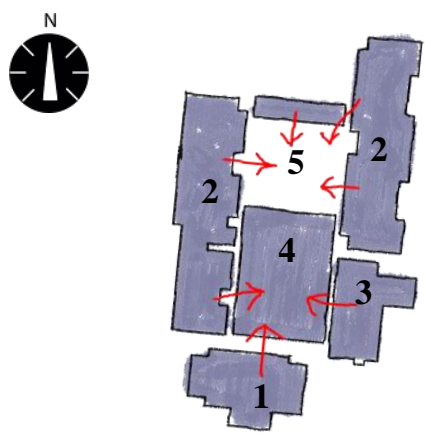

Figura 2 - Implantação dos blocos no terreno -

Fonte: Autora Karoline Nascimento (2018)

Nesse tipo de disposição, observa-se que um dos blocos pedagógicos ficou voltado para a orientação leste, o que seria a orientação ideal para ambientes de longa permanência, atendendo aos preceitos bioclimáticos da cidade de Recife, e que também se adequa a uma das salas, o berçário, onde as crianças de 0 a 1 ano, podem receber, nos solários, o sol da manhã, recomendado para sua faixa etária.

Por outro lado, as outras salas de atividades de longa permanência estão orientadas para a direção oeste e recebem a maior parte da incidência solar, 
principalmente no período da tarde. Foi observado também que, por conta disso, durante as aulas, à tarde, os alunos da pré-escola, que são alocados nesse bloco, mudam de lugar o mobiliário para que as carteiras não fiquem próximas às janelas, onde a radiação solar incide diretamente, conforme visto na Figura 03, que apresenta uma salas de aula espelhada em projeto, entretanto, como a visita foi realizada durante o período de férias escolares, as carteiras foram colocadas próximas a janela para comprovar a incidência solar sobre elas.

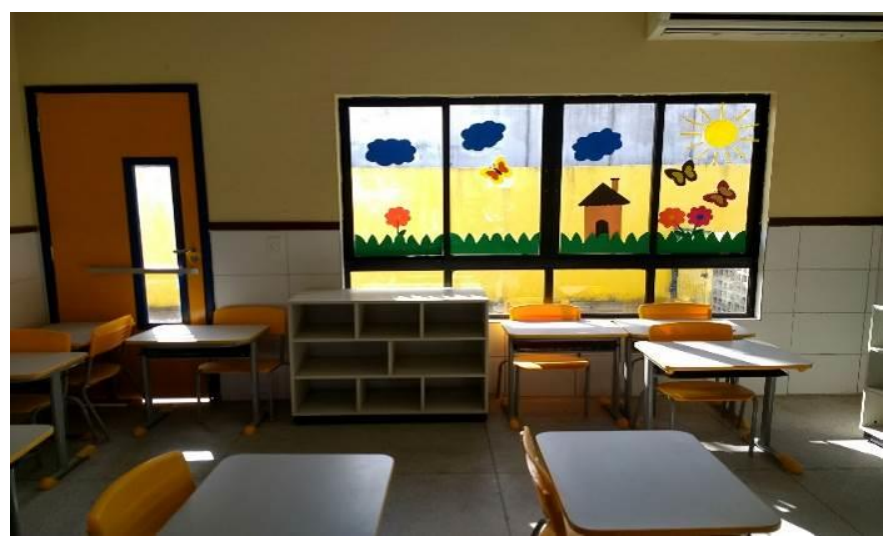

Figura 3 - Sala de aula da recebendo a incidência solar direta no período da tarde Fonte: Autora Karoline Nascimento (2018)

Tal situação poderia ser evitada ou minimizada caso existissem elementos de proteção solar nas janelas, como brises, ou caso o beiral avançasse mais do que o proposto, o suficiente para garantir o sombreamento, uma estratégia que evita o superaquecimento das superfícies, por geralmente estarem expostas à insolação direta (Figura 4).

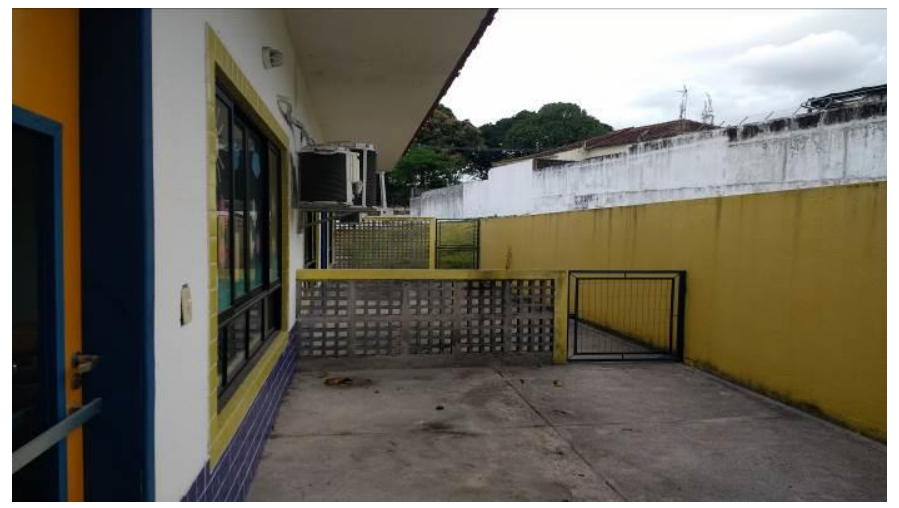

Figura 4 - A ausência de elementos de proteção na janela e as dimensões do beiral não são suficientes para evitar a insolação direta no período da tarde Fonte: Autora Karoline Nascimento (2018)

Além disso, os funcionários informaram que, a utilização de todas as salas, só é possível caso o sistema de climatização artificial esteja funcionando. No entanto, observou-se que em todas as salas, há janelas voltadas para o exterior, de tipo e dimensão que permitiriam a circulação da ventilação natural. É interessante destacar também que em algumas salas seria possível a ventilação cruzada, que permite a máxima circulação dos ventos internamente e a sua posterior saída. Quando questionados sobre essa possibilidade, afirmaram não ser possível devido à possibilidade de entrada de 
insetos. Entretanto, o memorial descritivo do Tipo "B" prevê a instalação de telas de proteção contra insetos nas janelas, o que, caso fossem instaladas, permitiria utilizar as janelas também abertas.

Dessa forma, percebe-se que um projeto padrão, apesar de vantagens como racionalização das construções e redução do tempo de obra, deve se preocupar também com a adequação climática, em termos de implantação, orientação solar e também dos ventos, pois a ventilação é importante não apenas para o conforto físico, mas também para a higienização dos ambientes. O uso da ventilação natural é um dos princípios básicos da arquitetura sustentável, ou da boa arquitetura, afinal, o vento é um recurso natural, gratuito e renovável.

Um dos elementos mais importantes do projeto é a incorporação dos princípios da acessibilidade, principalmente porque a proposta preza pela inclusão. A edificação é toda térrea e não possui muitos desníveis, sendo todos eles tratados com rampa com inclinação prescrita em norma (ABNT 9050/2015). Todos os banheiros são acessíveis, com barras laterais verticais, porta com giro de abertura para fora, área de transferência, entre outros. As portas das salas de aula possuem dimensão de $0,90 \mathrm{~m}$, além de maçaneta do tipo alavanca e barra lateral. É importante salientar que os acessos também atendem as dimensões mínimas, garantindo a independência de qualquer pessoa.

Os materiais de revestimento seguem ao ditado na cartilha do programa. A maior parte do piso é em granilite, nas áreas externas e internas, com exceção dos banheiros, em revestimento cerâmico, assim como nas paredes de todos os ambientes até $1,10 \mathrm{~m}$ de altura. Os revestimentos externos, utilizam revestimento cerâmico e pintura, de cor branca e com superfície texturizada. O uso de cores claras combinadas com revestimentos cerâmicos ou azulejos, lisos e polidos, auxiliam na reflexão da incidência direta e indireta do sol nas fachadas, enquanto um revestimento em pintura acrílica transmitirá a maior da parte da radiação.

O mobiliário também vem especificado, independentemente do tipo escolhido. Ele é direcionado de acordo com a divisão das salas: berçário, creche I, creche II, creche III e pré-escola, que leva em consideração a faixa etária das crianças, sendo padronizado e distribuído de acordo com a quantidade de crianças atendidas. A sala de multimídia possui mesas interativas, voltadas para os alunos da creche III e pré-escola, como uma forma de complemento da aprendizagem, uma vez que tornam a alfabetização mais lúdicas e possuem atividades que estimulam o raciocínio lógico, a memorização e a paciência.

\subsection{Resultado da satisfação dos usuários}

Os funcionários demonstraram sua insatisfação com um dos materiais de revestimento do piso, o granilite, por soltar pequenos grânulos da areia existentes em sua constituição, exigindo a constante limpeza. Com relação ao tamanho dos ambientes, a maioria considerou ideal para a realização das atividades propostas, como por exemplo, o berçário, que possui espaço suficiente para a quantidade de tapetes emborrachados espalhados na sala, para que os bebês possam engatinhar com segurança, bem como, as salas de aula da pré-escola, que além das mesas e cadeiras possuem armários para materiais e livros. Houve quem reclamasse da ausência de um ambiente de 
espera na recepção, que possui apenas um visor para o atendimento dos pais, entre a recepção e a secretaria.

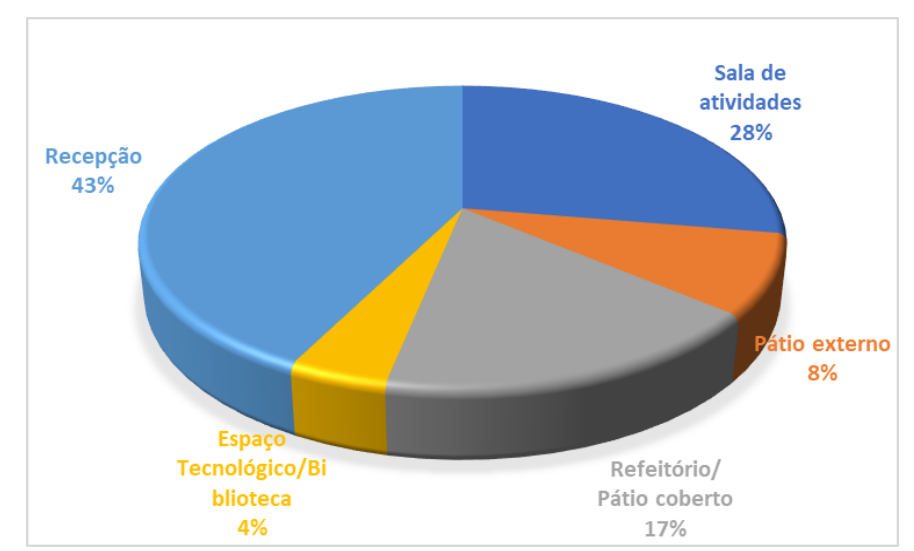

Figura 7 - Gráfico com resultados dos ambientes considerados mais quentes Fonte: Autora Karoline Nascimento (2018)

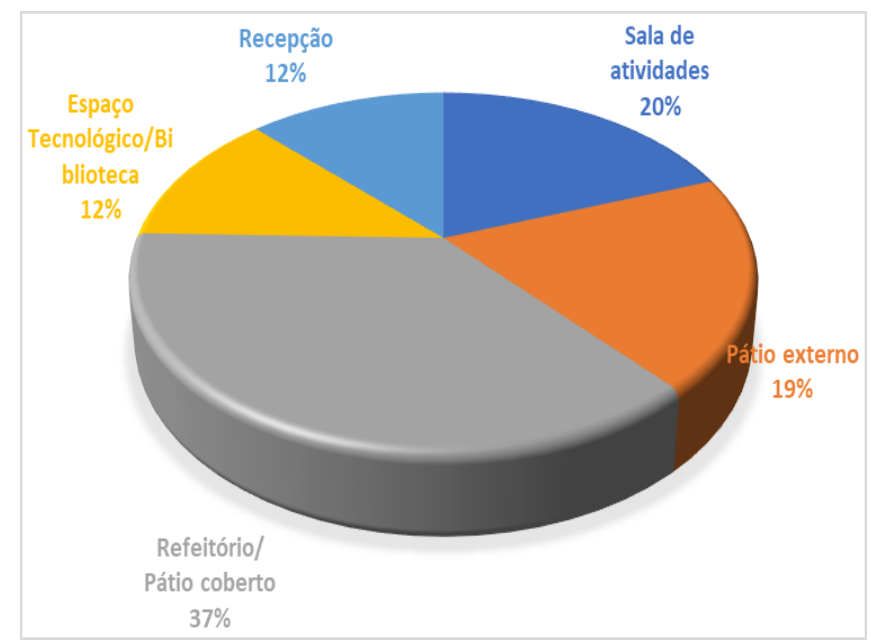

Figura 8 - Gráfico com resultados dos ambientes com maior intensidade de ruído Fonte: Karoline Nascimento (2018)

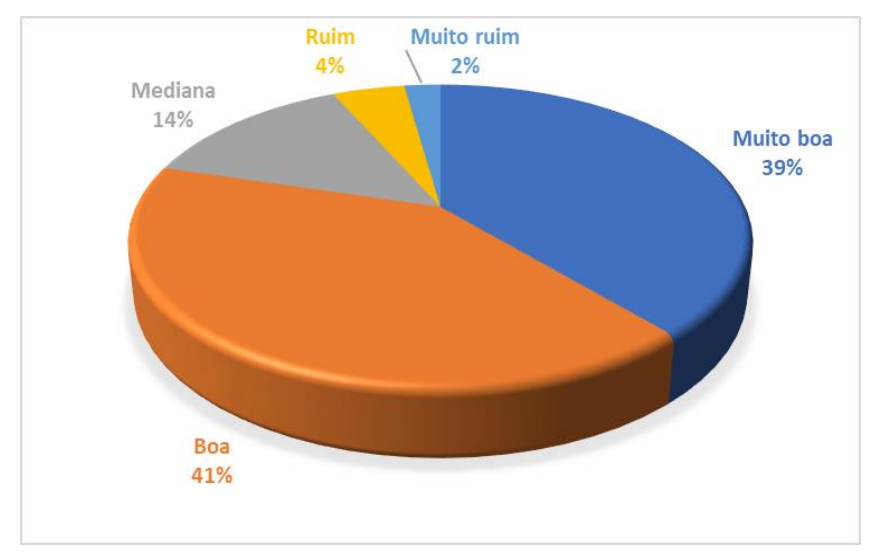

Figura 9 - Gráfico com resultados da satisfação com manutenção da creche. Fonte: Karoline Nascimento (2018)

O cruzamento das informações dos questionários e do passeio Walkthrough gerou gráficos de onde foi possível saber quais os ambientes mais quentes (Figura 7) - do ponto de vista da sensação de calor -, os ambientes com maior intensidade de ruído (Figura 8) - do ponto de vista do incômodo com o 
barulho -, se a manutenção da creche era satisfatória, assim como a sua (Figura 9), entre outros.

\section{CONSIDERAÇÕES FINAIS}

A Avaliação Pós-ocupação evidenciou que a implantação de um projeto padrão sem as adaptações ambientais e sociais necessárias tornou o equipamento problemático em diversos aspectos, principalmente do ponto de vista do conforto ambiental. Entretanto, é importante destacar que o atendimento às normas de acessibilidade é um grande ponto positivo da proposta.

Tal reprodução em massa tem gerado edificações com baixa eficiência funcional, devido ao uso de materiais ou sistemas construtivos que não se adequam às condições climáticas locais ou às questões socioculturais, sub ou super dimensionadas - muitas vezes por não considerar que o tamanho do tipo (Tipo 1, Tipo 2, Tipo 3, Tipo B e Tipo C) escolhido não se adequa à demanda local - e que acabam gerando um sentimento de insatisfação por parte dos usuários, o que pode comprometer a aprendizagem ou desenvolvimento, uma vez que o espaço tem influência no ser humano (BLOWER, 2008, p. 21).

É importante levar em consideração que o ambiente físico da creche é, por essência, o local de desenvolvimento do processo de ensino-aprendizagem. $\bigcirc$ edifício escolar deve ser analisado como resultante da expressão cultural de uma comunidade, por refletir e expressar aspectos que vão além de sua materialidade (KOWALTOWSKI, 2011, p. 11).

Enfatiza-se, no entanto, que não é só a criança quem se desenvolve, o contato entre os pais possibilita a troca de experiências e o compartilhamento de estratégias para solução de problemas comuns a essa fase. Portanto, o espaço profissional deverá permitir a promoção, além do desenvolvimento intelectual da criança e de sua segurança física, a sua socialização, através de atividades de lazer a serem realizadas com diversos grupos.

\section{REFERÊNCIAS}

BLOWER, H. C. S. O lugar do ambiente na educação infantil: Estudos de Caso na creche Doutor Paulo Niemeyer. Dissertação (Mestrado em Ciências da Arquitetura) - Programa de Pós-Graduação da Faculdade de Arquitetura e Urbanismo, Universidade Federal do Rio de Janeiro, Rio de Janeiro, 2008, 180 p.

BRASIL. Lei $\mathbf{n}^{\circ} \mathbf{8 . 0 6 9}$ de $\mathbf{1 3}$ de julho de 1990. Estatuto da Criança e do Adolescente.

ELALI, G. A. Ambientes para educação infantil: um quebra cabeça?

Contribuição metodológica na avaliação pós ocupação de edificações e na elaboração de diretrizes para projetos arquitetônicos na área. 2 v. Tese (Doutorado em Estruturas Ambientais Urbanas) - Faculdade de Arquitetura e Urbanismo, Universidade de São Paulo, São Paulo, 2002.

KOWALTOWSKI, D. C. C. K. Arquitetura escolar: o projeto do ambiente de ensino. São Paulo: Oficina de textos, 2011.

MEC. Proinfância. Creches e pré-escolas seguem projeto arquitetônico padrão. Brasília, junho do 2013. Disponível em: 
<http://portal.mec.gov.br/ultimas-noticias/207-1625150495/18810-creches-epre-escolas-seguem-projeto-arquitetonico-padrao>. Acesso em: 12 jan. 2018.

OLIVEIRA, G. A. Ergonomia Informacional na Travessia de Pedestre. 2009. 299p. Tese (Doutorado) - Departamento de Artes e Design, Pontifícia Universidade Católica do Rio de Janeiro, Rio de Janeiro, 2009.

ORNSTEIN, S. W. Avaliação Pós-Ocupação (APO) do ambiente construído. Marcelo Roméro (colaborador). São Paulo: Studio Nobel, 1992.

RHEINGANTZ, P. A.; AZEVEDO, G. A.; BRASILEIRO, A.; ALCANTARA, D.; QUEIROZ, $M$. Observando a qualidade do lugar: Procedimentos para a Avaliação PósOcupação. Rio de Janeiro: PROARQ/FAU/UFRJ, 2009. 